\title{
Condutividade elétrica em função do teor de água inicial de sementes de amendoim
}

\author{
Electrical conductivity and water content in peanut seeds
}

\section{Rafael Marani Barbosa ${ }^{\mathrm{I}^{*}}$ Clíssia Barboza da Silva ${ }^{\mathrm{I}}$ Maria Aparecida de Medeiros ${ }^{\mathrm{II}}$ Maria Aparecida Pessôa da Cruz Centurion ${ }^{\mathrm{I}}$ Roberval Daiton Vieira ${ }^{\mathrm{I}}$}

RESUMO

O vigor de sementes de amendoim (Arachis hypogaea L.) avaliado pelo teste de condutividade elétrica demonstra estreita relação com o desempenho no campo, mas alguns fatores podem afetar o resultado da condutividade elétrica, sendo um destes o teor de água inicial das sementes. Assim, o objetivo deste trabalho foi avaliar o teor de água ou faixa de umidade da semente mais adequado para a avaliação da condutividade elétrica em sementes de amendoim. Quatro lotes de sementes da cultivar 'IAC Tatu ST' e quatro da cultivar 'IAC Runner 886' foram avaliados quanto ao seu potencial fisiológico e posteriormente o teor de água foi ajustado para $5,7,9,11,13$ e $15 \%$, pelo método da atmosfera úmida. $O$ delineamento foi inteiramente casualizado em esquema fatorial $4 \times 6$ (lotes $\times$ teores de água) para as sementes de cada cultivar, em quatro repetições e os resultados para o fator teor de água foram submetidos à análise de regressão. A maior relação da condutividade elétrica com vigor das sementes ocorreu naquelas com teor de água entre 9 a 15\%, de forma que sementes com 5 a $7 \%$ de umidade não devem ser submetidas ao teste de condutividade elétrica, porque os lotes expressam alto padrão de germinação e vigor. A condutividade elétrica de sementes de amendoim é influenciada pelo teor de água e a estabilização dos resultados ocorre quando elas estão com teor de água entre 10 e $14 \%$.

Palavras-chave: Arachis hypogaea L., lixiviação, cultivares, vigor, germinação.

\section{ABSTRACT}

The vigor of peanut seeds (Arachis hypogaea L.) assessed by the conductivity test shows close relationship with performance in the field, but some factors may affect the outcome of the electrical conductivity, being one of that the initial water content of seeds. The objective of this study was to evaluate the seed water content most appropriate for evaluating the seed vigor through electrical conductivity test in peanut. Four seed lots of 'IAC Tatu ST' cultivar and four 'IAC Runner 886' were initially evaluated for their physiological potential and subsequently the seed water content was adjusted to 5, 7, $9,11,13$ and $15 \%$ by the method of controlled atmosphere. A completely randomized design with treatments arranged in a $4 \times 6$ factorial design (seed lots $\times$ seed water content levels) for each cultivar and four replications were used. The results for the factor seed water content were subjected to the analysis regression. The higher relationship of electrical conductivity and seed vigor occurred when the seed lots presents seed moisture content varying from 9 to $15 \%$. Seeds with $5-7 \%$ moisture should not be subjected to electrical conductivity test, because lots express high standard germination and vigor. The electrical conductivity of peanut seeds is influenced by the seed moisture content and the stabilization of the results occurs when the seeds have moisture content between 10 and 14\%.

Key words: Arachis hypogaea L., leakage, cultivars, vigour, germination.

\section{INTRODUÇÃO}

A utilização de sementes de alta qualidade é componente essencial para a implantação de qualquer sistema de cultivo, pelo fato de assegurar populações adequadas de plantas, em ampla faixa de condições ambientais e, consequentemente, permitir a expressão do potencial máximo da cultivar em questão.

'Departamento de Produção Vegetal, Faculdade de Ciências Agrárias e Veterinárias (FCAV), Universidade Estadual Paulista "Júlio de Mesquita Filho" (UNESP), 14883-900, Jaboticabal, SP, Brasil. Email: rmarani@gmail.com. *Autor para correspondência.

"Departamento de Ciências Vegetais,Universidade Federal Rural do Semi-árido (UFERSA), Mossoró, RN, Brasil. 
Oficialmente, a avaliação da qualidade de sementes é realizada pelo teste de germinação, conduzido em condições ótimas (temperatura, disponibilidade hídrica e oxigênio). Além desse teste, as empresas produtoras de sementes têm usado os testes de vigor para identificar diferenças no desempenho de lotes de sementes, como forma de destacar lotes com maior eficiência para o estabelecimento da população de plantas no campo, particularmente entre aqueles com padrão de germinação alto e similar.

Considerando-se que os testes de vigor fornecem índices mais sensíveis do potencial fisiológico, quando comparados ao teste de germinação (MARCOS FILHO, 2005; BAALBAKI et al., 2009), qualquer evento que preceda a perda do poder germinativo pode servir como base para o desenvolvimento de testes de vigor. Entretanto, acredita-se que, quanto mais próximo da maturidade fisiológica (ou mais distante da perda do poder germinativo) estiver a variável avaliada, mais sensível deverá ser o teste. Como a degradação das membranas celulares constitui-se, hipoteticamente, no primeiro evento do processo de deterioração (DELOUCHE \& BASKIN, 1973), os testes que avaliam a integridade de membranas seriam, teoricamente, os mais sensíveis para estimar o vigor de lotes de sementes.

Trabalhos realizados com sementes de amendoim (VANZOLINI \& NAKAGAWA, 1999) e soja (VIEIRA et al., 2002; 2004) apontaram que a determinação da condutividade elétrica da solução de embebição tem sido proposta como um teste bastante sensível para avaliar o vigor, uma vez que no processo de deterioração um dos eventos iniciais é a perda da integridade das membranas. Nas sementes com baixo vigor, há maior desorganização na estrutura das membranas celulares, permitindo aumento na lixiviação de solutos para o meio externo.

Entretanto, têm sido bastante estudado fatores que podem interferir nos resultados do teste de condutividade elétrica, a exemplo do teor de água das sementes, que, por ocasião da realização do teste, é de extrema importância na padronização do método, bem como na obtenção de resultados consistentes e reproduzíveis entre e dentro de um mesmo laboratório. Dependendo da espécie, da região de produção, da época de colheita, da eficiência da secagem e do ambiente, pode-se ter uma amplitude de variação muito grande entre os valores, independente do vigor das sementes (VIEIRA et al., 2002).

Em geral, tem-se verificado que teores de água muito baixos $(\leq 10 \%)$ ou muito altos $(\geq 17 \%)$ influenciam significativamente nos resultados no teste de condutividade elétrica, de modo que, para sementes de soja e ervilha, tem-se recomendado teor de água variando entre 10 e $15 \%$ para a obtenção de resultados comparáveis (LOEFFLER et al., 1988; HAMPTON et al., 1992). Assim, essa interferência está clara para sementes de soja (VIEIRA et al., 2002) e ervilha (BAALBAKI et al., 2009; COSTA et al., 2008), porém não foi evidenciada para sementes de milho (FESSEL et al., 2006).

No caso do amendoim, há relatos de que o teste de condutividade pode ser realizado em sementes com teor de água inferior a $10 \%$ (VANZOLINI \& NAKAGAWA, 1999). Entretanto, o assunto não está totalmente esclarecido, tendo em vista que o comércio e o armazenamento de sementes de amendoim é feito com teores de água mais baixo do que ocorre em sementes de ervilha e soja. Quando o teor de água das sementes de ervilha e soja foi muito baixo $(\leq 10 \%)$, verificou-se aumento significativo nos resultados do teste sem necessariamente ter redução do vigor (VIEIRA et al., 2002). Desse modo, é importante que se conheça o comportamento da condutividade em função do teor de água das sementes, independente do nível de vigor.

Diante do exposto, o objetivo deste trabalho foi avaliar o teor de água ou faixa de umidade da semente mais adequado para a avaliação da condutividade elétrica em sementes de amendoim.

\section{MATERIAL E MÉTODOS}

O experimento foi realizado no Laboratório de Análise de Sementes do Departamento de Produção Vegetal da UNESP, Campus de Jaboticabal, com sementes de duas cultivares de amendoim - 'IAC Tatu ST', pertencente ao grupo Valência, e 'IAC Runner 886', do grupo Virgínia. Quatro lotes de cada cultivar foram submetidos às avaliações de germinação e vigor (primeira contagem, envelhecimento acelerado e condutividade elétrica) para caracterização do seu potencial fisiológico.

Inicialmente, foram determinados o teor de água das sementes, a germinação e vigor dos lotes e logo após realizou-se o ajuste do teor de água para seis níveis $(5,7,9,11,13$ e 15\%). Com base no teor de água inicial, calculou-se a massa que a amostra de sementes deveria atingir para obter os teores prédefinidos; as amostras que necessitaram de secagem foram colocadas em estufa com circulação de ar forçada regulada à temperatura de $33^{\circ} \mathrm{C}$, em bandejas de plástico, permanecendo nessas condições até atingirem o teor de água desejado, sendo o monitoramento realizado por meio de pesagens 
sucessivas até atingirem o peso adequado para aquele teor de água. As sementes que necessitaram de aumento da massa foram submetidas ao processo de atmosfera úmida (ROSSETO et al., 1995), dispostas sobre tela adaptada em caixas de plástico $(28,5 \times 18,5 \times 10,0 \mathrm{~cm})$ contendo em seu interior $200 \mathrm{~mL}$ de água destilada, promovendo atmosfera de aproximadamente $100 \%$ de umidade relativa do ar, permitindo, dessa forma, que as sementes adquirissem água do ambiente.

O monitoramento do teor de água foi realizado durante o processo por meio de pesagens sucessivas até a obtenção dos valores desejados. Em seguida, as sementes foram embaladas em sacos de plástico e mantidas em câmara fria $\left(10^{\circ} \mathrm{C}, 50-60 \%\right.$ de umidade relativa do ar) por sete dias, para atingirem o equilíbrio higroscópico (MARCOS FILHO, 2005), sendo posteriormente submetidas ao teste de condutividade elétrica e à determinação do teor de água.

Teor de água da semente: para cada lote, foram utilizadas duas amostras de 20 sementes e a determinação foi realizada pelo método da estufa à temperatura de $105 \pm 3^{\circ} \mathrm{C}$ durante 24 horas (BRASIL, 2009), cujos resultados foram expressos em porcentagem (base úmida). Teste de germinação: foi conduzido com quatro subamostras de 50 sementes para cada lote, distribuídas em rolo de papel, tipo Germitest, previamente umedecido com água destilada com quantidade equivalente a 2,5 vezes o peso do substrato seco e mantidas em germinador à temperatura constante de $25^{\circ} \mathrm{C}$, com contagens realizadas aos cinco e dez dias após a semeadura (BRASIL, 2009). Teste de envelhecimento acelerado: foram utilizadas 220 sementes para cada lote, distribuídas em caixas de plástico $(11,0 \times 11,0 \times 3,5 \mathrm{~cm})$, possuindo em seu interior telas de alumínio acoplada, sobre a qual as sementes foram colocadas em camada única. Em cada caixa, foram adicionados $40 \mathrm{~mL}$ de água destilada, as quais foram mantidas em câmara de germinação, à temperatura de $41^{\circ} \mathrm{C}$ por 48 horas (MARCOS FILHO, 1999). Após o período de envelhecimento, as sementes foram submetidas ao teste de germinação (BRASIL, 2009) e as leituras realizadas no quinto dia após instalação do teste. Teste de condutividade elétrica: foi realizado com quatro subamostras de 50 sementes por lote, pesadas em balança analítica com precisão de $0,01 \mathrm{~g}$ e imersas em $75 \mathrm{~mL}$ de água desionizada em copos de plástico $(200 \mathrm{~mL})$. As sementes foram mantidas a temperatura constante de $25^{\circ} \mathrm{C}$ durante 24 horas em câmaras de germinação tipo B.O.D. Após esse período, foi determinada a condutividade elétrica da solução de embebição das sementes, em condutivímetro Digimed
CD-31 e os resultados expressos em $\mu \mathrm{S} \mathrm{cm}^{-1} \mathrm{~g}^{-1}$ (MARCOS FILHO \& VIEIRA, 2009).

O delineamento experimental utilizado foi o inteiramente casualizado, em esquema fatorial $4 \times 6$ (lotes $\times$ teores de água), em quatro repetições. As análises de variância foram realizadas separadamente para cada cultivar e foi feita análise de regressão polinomial para teor de água das sementes, sendo as médias das avaliações de germinação e vigor comparadas pelo teste de Tukey a 5\% de probabilidade. Os dados que não se ajustaram a uma distribuição normal foram transformados em arc sen $(\mathrm{x} / 100)^{0,5}$ (BANZATTO \& KRONKA, 2006).

\section{RESULTADOS E DISCUSSÃO}

Os resultados obtidos para teor de água, germinação e vigor (primeira contagem, envelhecimento acelerado e condutividade elétrica) de sementes de amendoim estão contidos na tabela 1 , pelos quais se verificou padrão semelhante no teor de água inicial das sementes, pois todos os lotes situaram-se próximos a 7\%, com uma pequena variação nos teores para os lotes da cultivar 'Tatu ST' (0,3 pontos percentuais) e 'Runner 886' ( 0,2 pontos percentuais). Com base nos testes de germinação e vigor, todos os lotes foram classificados como de alto potencial fisiológico, não havendo diferenças estatísticas entre os lotes de cada cultivar.

As sementes, ao atingirem o equilíbrio higroscópico, foram avaliadas quanto ao teor de água e verificou-se que este método foi eficaz para o ajuste aos níveis pré-estabelecidos. Tanto na secagem quanto na ocasião do ganho de água, as sementes da cultivar 'Tatu ST' levaram menos tempo para atingir os teores desejados. $\mathrm{O}$ fato pode ser explicado pelo maior tamanho de sementes da cultivar 'Runner 886', pois sementes grandes necessitam de maiores quantidades de água para entrar em equilíbrio com a atmosfera úmida, o que reduziu a velocidade no processo de ganho de água.

O objetivo deste trabalho não foi comparar a eficiência do método da atmosfera úmida frente a outros procedimentos, mas vale lembrar que diferentes métodos podem influenciar no potencial fisiológico de forma diferenciada (COSTA et al., 2008). Por exemplo, o método da atmosfera úmida diferencia-se da embebição entre folhas de papel no que diz respeito à velocidade de entrada de água nas sementes, podendo prejudicálas, principalmente, devido a danos por embebição (MARCOS FILHO, 2005). Portanto, recomendam-se maiores investigações que permitam relacionar métodos 
Tabela 1 - Teor de água inicial, germinação e vigor (primeira contagem da germinação, envelhecimento acelerado e condutividade elétrica) de sementes de amendoim das cultivares 'IAC Tatu ST' e' IAC Runner 886'. Jaboticabal, SP, 2010.

\begin{tabular}{|c|c|c|c|c|c|}
\hline Lotes & Teor de água & Germinação & Primeira contagem & $\begin{array}{c}\text { Envelhecimento } \\
\text { acelerado }\end{array}$ & $\begin{array}{l}\text { Condutividade } \\
\text { elétrica }\end{array}$ \\
\hline & \multicolumn{4}{|c|}{----------------------------------------------- $\%$----------------------------------------------- } & $\mu \mathrm{S} \mathrm{cm}^{-1} \mathrm{~g}^{-1}$ \\
\hline 1 & 6,9 & $88 \mathrm{a}^{1,2}$ & 77 a & $69 \mathrm{a}$ & $32,3 \mathrm{a}$ \\
\hline 2 & 7,0 & $91 \mathrm{a}$ & $83 \mathrm{a}$ & $71 \mathrm{a}$ & $29,1 \mathrm{a}$ \\
\hline 3 & 6,8 & $89 \mathrm{a}$ & $82 \mathrm{a}$ & $67 \mathrm{a}$ & $28,0 \mathrm{a}$ \\
\hline 4 & 7,1 & $84 \mathrm{a}$ & $74 \mathrm{a}$ & $64 \mathrm{a}$ & $30,2 \mathrm{a}$ \\
\hline 5 & 6,9 & $92 \mathrm{a}$ & $84 \mathrm{a}$ & $74 \mathrm{a}$ & $25,6 \mathrm{a}$ \\
\hline 6 & 6,8 & $85 \mathrm{a}$ & $74 \mathrm{a}$ & $66 \mathrm{a}$ & $27,6 \mathrm{a}$ \\
\hline 7 & 6,9 & $91 \mathrm{a}$ & $74 \mathrm{a}$ & $70 \mathrm{a}$ & $26,5 \mathrm{a}$ \\
\hline 8 & 7,0 & $92 \mathrm{a}$ & $84 \mathrm{a}$ & $73 \mathrm{a}$ & $24,7 \mathrm{a}$ \\
\hline DMS ('Tatu ST') & - & 8,5 & 9,3 & 7,9 & 5,7 \\
\hline DMS ('Runner 886') & - & 10,9 & 8,1 & 8,0 & 3,4 \\
\hline $\mathrm{CV}(\%)$ & - & 7,9 & 6,6 & 6,8 & 8,3 \\
\hline
\end{tabular}

${ }^{1}$ Médias seguidas da mesma letra não diferem estatisticamente entre si pelo teste de Tukey em nível de $5 \%$ de probabilidade. ${ }^{2}$ Dados originais, mas, para efeito de análise estatística, foram transformados em em arc sen $(\mathrm{x} / 100)^{0,5}$.

mais adequados aos objetivos propostos (RODRIGUES et al., 2006; COSTA et al., 2008).

Pelos resultados do teste de condutividade elétrica de sementes de amendoim, cultivares 'Tatu ST' e 'Runner 886' (Tabela 2), constatou-se que não houve distinção entre as médias dos diferentes teores de água das sementes, dentro de cada cultivar. Os valores de F para o fator teor de água foi altamente significativo, enquanto que para ofator lotes não houve significância, logo, o comportamento dos lotes foi o mesmo, dentro de cada cultivar; também não foram observadas interações significativas.

Os valores de condutividade elétrica diminuíram quando se aumentou o teor de água das

Tabela 2 - Condutividade elétrica $\left(\mu \mathrm{S} \mathrm{cm}^{-1} \mathrm{~g}^{-1}\right)$ de sementes de amendoim em função de lotes e teores de água inicial das cultivares 'Tatu ST' e 'Runner 886'. Jaboticabal, SP, 2010.

\begin{tabular}{|c|c|c|c|c|c|c|c|}
\hline \multirow{2}{*}{ Lotes } & \multicolumn{6}{|c|}{ 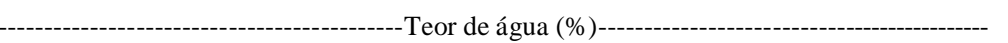 } & \multirow{2}{*}{ Média } \\
\hline & 5 & 7 & 9 & 11 & 13 & 15 & \\
\hline & \multicolumn{7}{|c|}{ - } \\
\hline 1 & 36,5 & 32,3 & 20,6 & 20,9 & 22,7 & 24,5 & $26,3 \mathrm{a}^{1}$ \\
\hline 2 & 34,1 & 29,1 & 21,8 & 21,1 & 22,8 & 22,7 & $25,3 \mathrm{a}$ \\
\hline 3 & 38,7 & 28,4 & 23,0 & 22,1 & 20,5 & 19,8 & $25,4 \mathrm{a}$ \\
\hline 4 & 33,9 & 30,2 & 22,4 & 22,0 & 22,0 & 20,6 & $25,2 \mathrm{a}$ \\
\hline 5 & 31,2 & 25,6 & 22,1 & 22,0 & 20,4 & 19,9 & $23,5 \mathrm{a}$ \\
\hline 6 & 33,8 & 27,6 & 20,7 & 21,2 & 20,4 & 18,6 & $23,7 \mathrm{a}$ \\
\hline 7 & 29,1 & 26,5 & 19,9 & 19,8 & 19,7 & 20,9 & $22,5 \mathrm{a}$ \\
\hline \multirow[t]{2}{*}{8} & 29,0 & 24,7 & 21,9 & 22,2 & 21,1 & 21,0 & $23,3 \mathrm{a}$ \\
\hline & \multicolumn{4}{|c|}{ Tatu ST } & \multicolumn{3}{|c|}{ Runner 886} \\
\hline Teste F & \multicolumn{4}{|c|}{$72,91^{* *}$} & \multicolumn{3}{|c|}{$73,57^{* *}$} \\
\hline DMS (5\%) & \multicolumn{4}{|c|}{2,1} & \multicolumn{3}{|c|}{1,5} \\
\hline CV (\%) & \multicolumn{4}{|c|}{11,01} & \multicolumn{3}{|c|}{8,62} \\
\hline
\end{tabular}

${ }^{1}$ Médias seguidas da mesma letra não diferem estatisticamente entre si pelo teste de Tukey em nível de $5 \%$ de probabilidade. ${ }^{* *}$ Significativo em nível de $1 \%$ pelo Teste $\mathrm{F}$. 
sementes, com tendência de estabilização dos resultados para as sementes das duas cultivares a partir de $10 \%$ do teor de água (Tabela 2 e Figura 1). Comportamento semelhante foi observado entre os resultados da condutividade elétrica de sementes de soja (LOEFFLER et al., 1988; VIEIRA et al., 2002), quando se verificou que houve estabilização em sementes com 11 e $13 \%$ de umidade. O aumento no valor da condutividade elétrica, em função da diminuição do teor de água das sementes está relacionado com o processo de reorganização das membranas celulares, em função da reidratação da semente. Quanto menor o teor de água da semente, maior o estado de desorganização da membrana celular, logo, maior o tempo necessário para que ocorra a reorganização desta e, consequentemente, redução da lixiviação, quando comparada a sementes com maior teor de água (BEWLEY \& BLACK, 1985).

Durante o processo de hidratação, as sementes podem sofrer danos por embebição, tendo em vista a velocidade com que a água penetra no interior delas. Esse dano ocorre quando diferenças acentuadas entre os potenciais hídricos da semente e do meio em que se encontram desencadeiam alterações na conformação e estrutura do sistema de membranas (HOEKSTRA et al., 1999), devido à entrada muito rápida de água nas sementes, o que ocasiona ruptura da estrutura celular e liberação de grande quantidade de solutos (MARCOS FILHO, 2005), elevando os valores de condutividade elétrica. Esses danos foram relatados

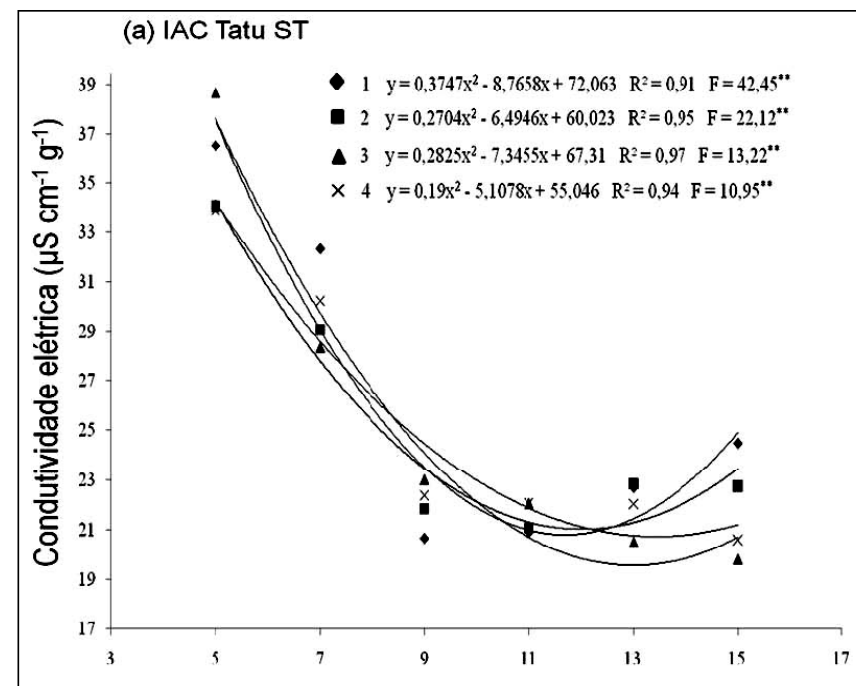

(b) IAC Runner 886

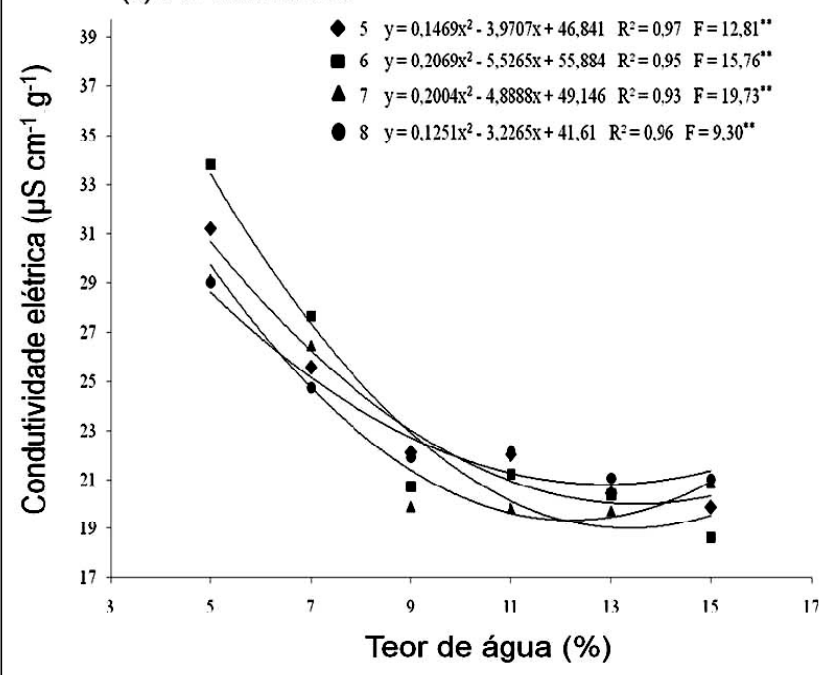

Figura 1 - Condutividade elétrica de sementes de amendoim, cultivar 'Tatu ST' (a) e 'Runner 886' (b), em função de teores de água. Jaboticabal, SP, 2010. 
tanto em sementes pequenas, como Brassica spp., no prazo de dois minutos do início da embebição (POWELL, 2006), como em sementes maiores, como as de soja (MARCOS FILHO, 2005).

$\mathrm{O}$ efeito do teor de água das sementes de amendoim foi mais evidente, ou seja, provocou maior aumento na condutividade elétrica para os teores de 5 e 7\%, concordando com VANZOLINI \& NAKAGAWA (1999) que obtiveram efeito marcante em sementes com $5 \%$ de umidade. Quanto menor o teor de água, maior a desorganização estrutural das membranas celulares e maior a perda de eletrólitos durante o período inicial de embebição(VIEIRA et al., 2004). Dentro desse contexto, sementes de amendoim com 5 a $7 \%$ de umidade não são indicadas para a condução do teste de condutividade elétrica, pois superestimam o resultado, condenando lotes que expressam alto padrão de germinação e vigor.

Por outro lado, tem-se que considerar que a comercialização e o uso de sementes de amendoim, tendo em vista sua morfologia e características químicas, ocorrem com teores de água nessa faixa de umidade, particularmente na principal região produtora do país, cuja produção é feita em áreas de reforma de canaviais. $\mathrm{O}$ armazenamento das sementes após a colheita e antes da próxima safra ocorre em período com predominância de baixa umidade relativa do ar, levando a ocorrência do equilíbrio higroscópico das sementes em baixos níveis de umidade. Assim, o uso e a determinação da condutividade elétrica para sementes de amendoim justificam-se nessa faixa, mesmo sabendo que possa ter interferência do seu teor de água. No caso do amendoim, talvez as considerações sejam opostas às da soja, cujo teor de água comum seria na faixa entre 10 e $13 \%$.

Os teores de 9 a $15 \%$, quando comparados entre si, para as sementes das duas cultivares assumem o mesmo comportamento, indicando que o percentual de umidade dentro desse intervalo não afetou o resultado da condutividade elétrica. VANZOLINI \& NAKAGAWA (1999) recomendaram que a condutividade elétrica fosse realizada em sementes com teor de água de 9\%, mas esse valor, de acordo com o presente trabalho, pode ser estendido até $14 \%$ (Figura 1), levando a uma redução no período de dessecação das sementes para que sejam submetidas à avaliação de vigor.

Nas duas cultivares e para todos os lotes, houve redução na condutividade elétrica à medida que o teor de água aumentou de 5 para $15 \%$, evidenciando que sementes hidratadas permitem reorganizar a estrutura das membranas celulares, reduzindo a permeabilidade e, consequentemente, a lixiviação de solutos. Dentro das sementes da cultivar 'Tatu ST', ocorreram as maiores variações nos resultados da condutividade elétrica e essa diferença situou-se na faixa de $14,7 \mu \mathrm{S} \mathrm{cm}^{-1} \mathrm{~g}^{-1}$, sendo que, para as sementes da cultivar 'Runner 886', a menor diferença foi de $10,9 \mu \mathrm{S}$ $\mathrm{cm}^{-1} \mathrm{~g}^{-1}$.

Para as análises de regressão polinomial (Figura 1), verificou-se significância, pois os resultados da condutividade elétrica para cada lote ajustaram-se a funções quadráticas positivas, indicando que a redução da liberação de exsudados ocorreu exponencialmente com o aumento do teor de água. Dessa forma, ressaltase a similaridade no que diz respeito ao decréscimo geral dos resultados de condutividade elétrica em relação ao aumento do teor de água das sementes para as duas cultivares, observando-se ainda o padrão de estabilidade dos resultados após $10 \%$ de umidade.

No ponto mínimo da regressão da condutividade elétrica, determinou-se o ponto de máximo vigor, sendo que, para a cultivar 'Tatu ST', esse ponto foi atingido quando o teor de água assumiu valores de 11,7; 12,0; 13,0 e 13,4\% nos lotes 1, 2, 3 e 4, respectivamente e, para o cultivar 'Runner 886', alcançou valores de 13,$5 ; 11,8 ; 12,2$ e $12,9 \%$ nos lotes $5,6,7$ e 8 , respectivamente.

A estabilização dos valores de condutividade elétrica ocorreu em sementes cujos teores de água situaram-se na faixa de 10 a $14 \%$, correspondendo ao maior potencial fisiológico dessas sementes. Como os lotes foram classificados em alto vigor e para que o teste de condutividade elétrica mensure o potencial fisiológico desses lotes, é necessário, portanto, que o teste seja realizado com sementes situadas nesses teores de água.

Entretanto, entende-se como grande dificuldade o fato de se trabalhar com sementes de amendoim com teores de água superiores a $10 \%$. A hipótese é que, nesse caso, os padrões de condutividade para as sementes da espécie sejam determinados com teores de água inferiores a $10 \%$, numa faixa entre 7 e $9 \%$, valores comuns para sementes de amendoim mantidas em armazéns convencionais na região de Jaboticabal e comercializadas para fins de semeadura. Isso sugere que outros trabalhos deverão ser conduzidos para esclarecer e definir essa situação, pois o ajuste para valores acima de $10 \%$ é trabalhoso e requer cuidados para que se obtenham dados consistentes.

\section{CONCLUSÃO}

A condutividade elétrica de sementes de amendoim é influenciada pelo teor de água, havendo estabilizaçãoquando elas estão com umidade entre 10e 14\%. 


\section{AGRADECIMENTOS}

À Cooperativa dos Plantadores de Cana-de-açúcar da Zona de Guariba (COPLANA), pelo fornecimento das sementes de amendoim.

\section{REFERÊNCIAS}

BAALBAKI, R. et al. Seed vigor testing handbook. Ithaca, NY, USA: Association of Official Seed Analysts, 2009. Contribution n.32.

BANZATTO, D.A.; KRONKA, S.N. Experimentação agrícola. 4.ed. Jaboticabal: FUNEP, 2006. 237p.

BEWLEY, J.D.; BLACK, M. Seeds: physiology of development and germination. New York: Plenum, 1985. 367p.

BRASIL. Ministério da Agricultura, Pecuária e Abastecimento. Regras para análise de sementes. Ministério da Agricultura, Pecuária e Abastecimento. Secretaria de Defesa Agropecuária. Brasília, DF: MAPA/ACS, 2009. 395p.

COSTA, C.J. et al. Pré-hidratação de sementes de ervilha e sua interferência na avaliação do potencial fisiológico. Revista Brasileira de Sementes, v.30, n.1, p.198-207, 2008. Disponível em: <http://www.scielo.br/scielo.php?script=sci_arttext\&pid=S0101$31222008000100025 \& \operatorname{lng}=$ pt\&nrm=iso $>$. Acesso em: 19 set. 2010. doi: $10.1590 / \mathrm{S} 0101-31222008000100025$.

DELOUCHE, J.C.; BASKIN, C.C. Accelerated aging techniques for predicting the relative storability of seed lots. Seed Science and Technology, v.1, n.2, p.427-452, 1973

FESSEL, S.A. et al. Electrical conductivity testing of corn seeds as influenced by temperature and period of storage. Pesquisa Agropecuária Brasileira, v.41, n.10, p.15511559, 2006. Disponível em: <http://www.scielo.br/ scielo.php? script=sci_arttext \& pid=S $0100-$ 204X2006001000013\&lng=em\&nrm=iso >. Acesso em: 19 set. 2010. doi: 10.1590/S0100-204X2006001000013.

HAMPTON, J.G. et al. Bulk conductivity test variables for mungbean, soybean and French bean seed lots. Seed Science and Technology, v.20, n.3, p.677-686, 1992.

HOEKSTRA, F.A. et al. Imbibitional leakage from anhydrobiotes revisited. Plant, Cell and Environment, v.22, n.9, p.11211131, 1999. Disponível em: <http://onlinelibrary.wiley.com/ doi/10.1046/j.1365-3040.1999.00491.x/pdf >. Acesso em: 10 jan. 2011. doi: 10.1046/j.1365-3040.1999.00491.x.
LOEFFLER, T.M. et al. The bulk conductivity test as an indicator of soybean seed quality. Journal of Seed Technology, v.12, n.1, p.37-53, 1988.

MARCOS FILHO, J. Fisiologia de sementes de plantas cultivadas. Piracicaba: FEALQ, 2005. 495p.

MARCOS FILHO, J. Testes de vigor importância e utilização. In: KRZYZANOWSKI, F.C. et al. (Ed.). Vigor de sementes: conceitos e testes. Londrina: ABRATES, 1999. Cap.1, p.1-21.

MARCOS FILHO, J.; VIEIRA, R.D. Seed vigor tests: procedures - conductivity tests. In: BAALBAKI, R. et al. (Org.). Seed vigor tests handbook. Ithaca, NY, USA: AOSA, 2009. p.186200 .

POWELL, A.A. Seed vigour and its assessment. In: BASRA, A.S. (Org.). Handbook of seed science and technology. New York, Food Products, 2006. p.603-648.

RODRIGUES, M.B.C. et al. Pré-hidratação em sementes de soja e eficiência do teste de condutividade elétrica. Revista Brasileira de Sementes, v.28, n.2, p.168-181, 2006. Disponível em: $<$ http://www.scielo.br/scielo.php?script=sci_arttext\&pid=S0101$31222006000200023 \& \operatorname{lng}=$ pt\&nrm=iso>. Acesso em: 19 set. 2010. doi: $10.1590 / \mathrm{S} 0101-31222006000200023$.

ROSSETO, C.A.V. et al. Metodologias de ajuste do grau de umidade e comportamento de sementes de soja no teste de germinação. Revista Brasileira de Sementes, v.17, n.2, p.171-178, 1995

VANZOLINI, S.; NAKAGAWA, J. Teste de condutividade elétrica em sementes de amendoim: efeitos de teor de água inicial e de período de embebição. Revista Brasileira de Sementes, v.21, n.1, p.46-52, 1999. Disponível em: <http:/ /www.abrates.org.br/revista/artigos/1999/v21n1/artigo07.pdf>. Acesso em: 19 set. 2010.

VIEIRA, R.D. et al. Condutividade elétrica e o teor de água inicial das sementes de soja. Pesquisa Agropecuária Brasileira, v.37, n.19, p.1333-1338, 2002. Disponível em: $<$ http://www.scielo.br/scielo.php?script=sci_arttext\&pid=S0100204X2002000900018\&lng=em\&nrm=iso >. Acesso em: 21 set. 2010. doi: 10.1590/S0100-204X2002000900018.

VIEIRA, R.D. et al. Electrical conductivity of the seed soaking solution and soybean seedling emergence. Scientia Agricola, v.61, n.2, p.164-168, 2004. Disponível em: <http:// www. scielo.br/scielo.php? script $=$ sci_arttext\&pid $=$ S0 103 $90162004000200007 \& \operatorname{lng}=e n \& n r m=i s o>$. Acesso em: 21 set. 2010. doi: 10.1590/S0103-90162004000200007. 